\title{
ENSINO REMOTO EMERGENCIAL NA EDUCAÇÃO SUPERIOR: UMA REFLEXÃO BASEADA EM PAULO FREIRE
}

\author{
LUCAS SOCOLOSKI GUDOLLE \\ Instituto Federal de Educação, Ciência e Tecnologia de Roraima (IFRR) Campus Avançado \\ Bonfim, Roraima, Brasil \\ ALESSANDRA BLANDO \\ SÉrgio Roberto KieLING Franco \\ Universidade Federal do Rio Grande do Sul (UFRGS), Porto Alegre, Rio Grande do Sul, \\ Brasil
}

Resumo: Neste ensaio buscou-se problematizar o ensino remoto emergencial no contexto da educação superior durante a pandemia de COVID-19. Para tal, partiuse das concepções de educação bancária e de educação libertadora proposta por Paulo Freire, em sua principal obra Pedagogia do Oprimido. Apresentam-se também questionamentos acerca do ensino remoto emergencial como uma prática tradicional que segue se perpetuando, apesar do uso das tecnologias digitais da informação e comunicação (TDICs). Ao final, abordam-se as possíveis dificuldades enfrentadas por educadores e educandos nessa transição do ensino presencial para o ensino remoto emergencial.

Palavras-chave: Ensino Remoto Emergencial. Pandemia. Educação Bancária. Educação Problematizadora.

\section{INTRODUÇÃO}

Este ensaio visa a problematizar o Ensino Remoto Emergencial (ERE) na educação superior durante a situação pandêmica provocada pelo novo coronavírus (Sars-CoV2), tendo como referencial principal as ideias de Paulo Freire. Parte-se da perspectiva de que a riqueza do pensamento freireano permite que se faça uma análise inclusive sobre contextos não esperados, como é o caso da atual pandemia.

Devido à situação emergencial de saúde por conta do agravamento da pandemia de COVID-19 as Instituições de Ensino Superior (IES) precisaram adaptar suas atividades de ensino, adotando estratégias para um Ensino Remoto Emergencial, sempre que possível, em substituição ao ensino presencial, inclusive atendendo ao que foi recomendado pelo Conselho Nacional de Educação (Parecer CNE/CP N. ${ }^{\circ}$ 05/2020) (BRASIL, 2020). Visando a evitar a contaminação e a reduzir a propagação do COVID-19, o distanciamento físico entre as pessoas foi necessário, tornando o ERE a alternativa mais viável nesse contexto. Assim, o ensino universitário tornou-se remoto por acontecer distante no espaço, e emergencial por ter sido concebido às pressas, sobrepondo-se ao 
planejamento pedagógico anterior que havia sido pensado para a modalidade presencial (BEHAR, 2021).

Dessa forma, o que deveria acontecer no ensino presencial precisou ser repensado para os meios digitais, adaptando-se, a partir dos planos de ensino vigentes, metodologias, redistribuindo-se conteúdos, adotando-se novas formas de avaliação e criando-se atividades de recuperação. Tudo isso utilizando-se as tecnologias digitais da informação e comunicação (TDICs).

No ERE, as atividades presenciais não devem ocorrer e as aulas podem ser síncronas ou assíncronas, através de videoaula, gravadas ou fazendo-se uso de softwares de videoconferência. Entretanto, as atividades não se encerram nesses formatos. O ERE é, geralmente, composto também por um ambiente virtual de aprendizagem (AVA) que demanda dos alunos outras atividades assíncronas.

No Parecer CNE/CP no 5/2020, destacam-se algumas recomendações à educação superior que dizem respeito às atividades remotas, não presenciais ou a distância, como:

\begin{abstract}
adotar a substituição de disciplinas presenciais por aulas não presenciais; [...] definir a realização das avaliações de forma remota; implementar teletrabalho para professores e colaboradores; realização de atividades on-line síncronas de acordo com a disponibilidade tecnológica; oferta de atividades on-line assíncronas de acordo com a disponibilidade tecnológica (BRASIL, 2020, p. 18-19, grifo do autor).
\end{abstract}

O registro de frequência, anteriormente realizado de modo presencial e agora feito com a ajuda da internet, foi substituído pela presença na aula via conferência online. O diálogo entre educador e educandos, no contexto remoto, em aulas síncronas, dá-se pela participação e discussões quando o microfone é aberto e, por vezes, nos chats ao digitar suas contribuições. O movimento de se deslocar até a universidade não mais acontece e o acesso às salas de aula se dá via computador ou celular, através de um software de videoconferência. Além disso, como não é possível acessar as bibliotecas físicas, materiais e livros são disponibilizados no Ambiente Virtual de Aprendizagem (AVA).

Toda essa mudança emergencial impôs uma série de desafios a educadores e educandos, pois diferentemente do que já ocorre na modalidade de ensino a distância (EAD), na situação de ERE, normalmente não há uma equipe multiprofissional preparada para dar suporte às atividades pedagógicas com diferentes mídias em plataformas online. Desse modo, o cenário da pandemia reacendeu preocupações educacionais, como as condições de trabalho dos professores, a qualidade em que se dará os processos de ensino e de aprendizagem, a importância e os significados dos assuntos e conteúdos a serem tratados e discutidos, bem como o desenvolvimento de metodologias e de práticas pedagógicas centradas no estudante (MARTINS, 2020). E o trabalho remoto emergencial tem gerado "ansiedade, medo, mais competição, angústia, depressão e estresse desnecessários a pessoas cujo sentimento de aflição diariamente cresce dado o 
aumento do número de casos confirmados de contaminações e mortes em decorrência do coronavírus" (CERRI, 2020, p. 3).

A seguir são apresentadas as concepções de educação bancária e de educação libertadora de Paulo Freire, as quais buscou-se relacionar e problematizar com o ensino remoto emergencial no contexto da educação superior durante a pandemia de COVID19. Posteriormente, abordam-se as possíveis dificuldades enfrentadas por educadores e educandos nessa transição do ensino presencial para o ensino remoto emergencial.

\title{
EDUCAÇÃO BANCÁRIA
}

Paulo Freire, em sua obra Pedagogia do Oprimido, demonstra que a educação pode ser um dispositivo de opressão. $O$ autor relata sobre o método tradicional dos processos de ensino e de aprendizagem no qual o educador é quem tem a propriedade do conhecimento e o educando é aquele que obtém esse saber integralizado e concluso. A metodologia de ensino tradicional é marcada pela vocalidade, onde o educador transmite o saber e os educandos escutam para memorar e reprisar futuramente, sem, entretanto, outorgar acepção ao que estão comunicando. Aos educandos cabe a repetição desse conhecimento passado pelo educador. Esse processo é caracterizado pelas prescrições, narrações e faz dos educandos receptáculos ou armazéns para serem preenchidos pelos professores (FREIRE, 2018).

Essa concepção bancária do educador é, em essência, o modelo de opressão dos educandos, compreendendo as pessoas como se fossem contas bancárias, recipientes em que o conteúdo e o conhecimento são depositados ou transferidos para suas cabeças pela narração e distanciamento da realidade. É reducionista, pois coisifica as pessoas para oprimi-las, para controlar as suas ações e pensamentos; não permite que aconteça o diálogo e inibe o poder de criar e atuar, uma vez que os frustra com os obstáculos, deixando-os impotentes, submissos e alienados (FREIRE, 2018).

\begin{abstract}
A prática pedagógica dos educadores é permeada pelo autoritarismo, dizendo aos educandos o que devem fazer e o que responder; portanto, eles vivenciam uma pedagogia da resposta. Não é permitido realizar críticas, assim como não se deve questionar e nem duvidar do professor - aquele que detém o conhecimento e que irá depositá-lo no corpo "vazio" dos alunos. Isso pelo fato de a educação bancária não buscar a conscientização dos educandos (BRIGHENTE; MESQUIDA, 2016, p. 7).
\end{abstract}

Nesse caso, a educação "é puro treino, é pura transferência de conteúdo, é quase adestramento, é puro exercício de adaptação ao mundo" (FREIRE, 2000, p. 101).

A compreensão mecânica da consciência, como algo vazio a ser preenchido, é característico dessa concepção, como um mecanismo de dominação, em que prevalece a narrativa para manter a contradição entre educador e educando. Freire (2018) destaca o entendimento de Sartre, que chama essa concepção de alimentícia, digestiva, na qual o educar faz um tratamento de engorde ao introduzir nos educandos comunicados do falso saber para adaptar os homens ao mundo. Quanto mais adaptados ao mundo que a 
minoria dominadora prescreve, mais sujeitos e controlados estarão para reproduzir as finalidades e a continuidade dessa relação de opressores e oprimidos.

Os educandos assistem às aulas e aprendem pela exposição do professor detentor do saber e são estimulados a dificultar o pensar autêntico, uma vez que são controlados pelos métodos de avaliação, pelas indicações de leituras e bibliografia e pela imposição de sua fala. Não há diálogo nem intercomunicação, o educador é ativo nesse processo, enquanto os demais são passivos, subordinados e temerosos de sua autoridade.

Para a concepção bancária, é preciso que os educandos aprendam pela descrição ou depósitos do educador, que é detentor do objeto cognoscível. O educador faz o experimento em seu laboratório ou biblioteca, aprende e depois vai dar uma aula narrada, dissertando a respeito do que leu ou experimentou e deposita nos alunos esse conhecimento para que arquivem essas informações e as decorem para uma possível avaliação futura.

[..] Educador e educandos se arquivam na medida em que, nesta distorcida visão da educação, não há criatividade, não há transformação, não há saber. Só existe saber na invenção, na reinvenção, na busca inquieta, impaciente, permanente, que os homens fazem no mundo, com o mundo e com os outros: [...] (FREIRE, 2018, p. 58).

Por não existir o diálogo, o educador, por vezes, nem sabe o nome do aluno, não o vê como um ser humano complexo, apenas o visualiza como um receptor de seus conteúdos e experiências pessoais. Ao fazer muito uso da palavra e não abrir para interação em sala de aula, chega, até mesmo, a expor ao vexame aquele que se atrever a questionar, emitir sua opinião ou pensamento contrário. Por não escutar e não dialogar, não acompanha o desenvolvimento do aluno, ao invés disso, aplica uma avaliação para classificá-lo e reduzi-lo a um número.

Com a palavra, o homem se faz homem. Ao dizer a sua palavra, pois, o homem assume conscientemente sua essencial condição humana. E o método que lhe propicia essa aprendizagem comensura-se ao homem todo, e seus princípios fundam toda pedagogia, desde a alfabetização até os mais altos níveis do labor universitário (FIORI, 2018, p. 17).

Dessa forma, não é possível pensar em avanços no conhecimento, pois o aluno é convidado a memorizar a narrativa do educador, não havendo uma reflexão por parte dos alunos, já que o entendimento do educador é soberano e imposto. Sendo assim, a prática bancária na educação anestesia a criatividade dos educandos, não tendo interesse em estimular a invenção (criar o que é novo, aquilo que não existe). Apenas lhe interessa a inovação (aplicação de soluções para problemas já existentes) e com isso imobiliza e fixa ao produzir subjetividade. Entende-se que "a invenção é a descoberta 
GUDOLLE, L. S.; BLANDO, A.; FRANCO, S. R. K.

das relações científicas ou técnicas que tornam possível o novo modo de fazer coisas; a inovação é sua aplicação comercial" (BROWNE, 1985, p. 8). E para Freire (2018) não é no calar e no consentir que as pessoas se constituem, mas sim na palavra, no trabalho, na ação e no refletir que transformam a sua realidade e o mundo.

\footnotetext{
O corpo do indivíduo também é marcado e oprimido na medida em que é massificado, observa Freire (2003), pois ele não assume uma posição crítica perante a vida, sua consciência nada mais é que ingênua. Desse modo, homens e mulheres são passíveis de domesticação, o ser humano não possui mais endereço, torna-se "desenraizado" (BRIGHENTE; MESQUIDA, 2016, p. 9).
}

$\mathrm{Na}$ educação, seja ela a escolar ou a superior, ao primar-se por um ensino mecanicista e opressor, o educador assumirá essa função de domesticador dos educandos. Pretende tornar submissos os corpos e a consciência do aluno - que não é (e nem deve tentar ser) gerenciável pela IES -, como afirma Foucault (2009), indo ao encontro dos ideais de Paulo Freire. A educação bancária busca o controle do indivíduo que antes se dava pelo aprisionamento (FOUCAULT, 2009) em salas de aula e agora passa pela apreensão e o sequestro da sua subjetividade, por meio da tentativa do controle social do seu corpo.

No caso especificamente das IES, ao fundamentar-se em práticas de uma educação "bancária" conseguiriam formar sujeitos efetivamente críticos e conscientes? Quanto mais é imposto aos estudantes uma passividade, o lugar de transformação se coloca como o de alienação.

Um dos questionamentos que pode ser feito é o quanto uma prática de ensino presencial já alicerçada em uma concepção de educação bancária, opressora, pode ser diferente em um contexto de ensino remoto emergencial. Esse tipo de ensino poderia reforçar ou transformar a prática docente?

\section{EDUCAÇÃO LIBERTADORA}

A educação libertadora, essencialmente problematizadora e emancipatória, pretende localizar o ser humano no mundo, destacando o seu lugar na história e sua cultura. Pretende problematizar sua situação no mundo e libertá-lo da opressão, pois convida o ser humano a experimentar a aprendizagem, a criticar as verdades narradas, estimulando o pensar autêntico para transformar a si e ao mundo pela conscientização (FREIRE, 2018). Desse modo, o sujeito é o educando que busca o conhecimento e o saber a partir da reflexão sobre as suas vivências, dando espaço ao desenvolvimento da criatividade.

É prerrogativa da educação libertadora a busca pelo ser mais ${ }^{1}$, ou seja, a humanização dos homens. Isso somente é possível pelo diálogo entre educador e educando, superando essa contradição pela humanização de ambos, pois envolve o ato cognoscente no diálogo, na criação e na conscientização. Somente o diálogo, que implica um pensar crítico, será capaz de gerar e desenvolver a criticidade (FREIRE, 2018). 
Assim, os educandos são convidados a participar e a conhecer o objeto ou o conteúdo a ser aprendido, tornando-se mediatizadores da reflexão de ambos e por isso estão sempre aprendendo, seja quando estão estudando para a aula, seja quando estão dialogando em aula ou refletindo em conjunto. $O$ educando passará, então, a ser ativo do processo de conhecer e assim constrói seu saber. Nesse momento, se dá a superação da contradição educador-educando, uma vez que o conhecimento é investigado e compartilhado, um processo em que educando e educador aprendem e constroem conhecimento (FREIRE, 2018).

Quanto mais o educando for problematizado, mais ele se percebe como um ser no mundo e mais será desafiado a conhecer, a questionar e refletir sobre o seu papel no mundo. Esse desafio leva à emersão das consciências e a sua entrada crítica na realidade. Dessa forma, a educação se faz e refaz na práxis. "Para ser tem que estar sendo" (FREIRE, 2018, p. 102, grifo do autor).

Portanto, a educação libertadora é fundada na transformação e na mudança, não é inerte e passiva, se fazendo, então, revolucionária. Compreende que as pessoas são seres inconclusos, que constroem a sua história e a modificam, de modo que o processo de tomada de consciência de sua situação seja desafiador e que permita a reflexão, a superação e a mudança (FREIRE, 2018).

Segundo Freire (2001), o mestre que atua de modo humanista e revolucionário precisa, em conjunto com os educandos, efetuar suas atividades de forma crítica e humanizada, oportunizando que se construa uma relação que favoreça a conversação. Para que isso ocorra, é basilar se estabelecer no mesmo grau de convivência com os discentes.

O professor deveria ensinar seu educando a perguntar, ou melhor, possibilitar e oferecer esse espaço para seu corpo irrequieto, mas, na verdade, nem ele foi educado para isso. Daí a importância de uma educação libertadora para que educandos e educadores, juntos, se libertem (BRIGHENTE; MESQUIDA, 2016, p. 19).

Assim, o educador que pretende contribuir para o processo de libertação da opressão e de conscientização dos educandos não pode continuar participando de uma educação reprodutora. Educação essa calcada na repetição, característica do ensino bancário, algo que continua a ser ministrado em nossas escolas e universidades, ou seja, em todos os níveis de ensino (BECKER, 2010).

Uma das condições necessárias para que nos tornemos um intelectual que não teme a mudança é a percepção e a aceitação de que não há vida na imobilidade. De que não há progresso na estagnação. De que, se sou, na verdade, social e politicamente responsável, não posso me acomodar às estruturas injustas da sociedade. Não posso traindo a vida, bendizê-las. Ninguém nasce feito. Vamos nos fazendo aos poucos na prática social de que tomamos parte (FREIRE, 2014, p. 103). 
Diante do exposto, seria possível pensar (e realizar) a prática de uma educação libertadora em um contexto de ERE? Para se tentar responder a essas perguntas, é preciso tomar como ponto de partida as funções que uma universidade desempenha.

\begin{abstract}
[...] criação, desenvolvimento, transmissão e crítica da ciência, da técnica e da cultura, preparação para o exercício de atividades profissionais que exijam a aplicação de conhecimentos e métodos científicos para a criação artística; apoio científico e técnico ao desenvolvimento cultural, social e econômico das sociedades (PIMENTA, ANASTASIOU, 2002, p. 163).
\end{abstract}

Será possível que as IES, de fato, consigam cumprir esse papel em um contexto de ERE? Diante da situação da pandemia de COVID-19, o ERE se tornou a melhor opção para que a universidade siga tentando efetivar suas funções, preservando a saúde de seus educadores e educandos. No entanto, o que está em xeque é como o ERE pode ser implementado e realizado a partir de uma prática de educação libertadora.

Para uma prática de educação libertadora, a sala de aula, tanto a presencial como a virtual, deve visar à construção e, consequentemente, produção do conhecimento, através da promoção dos debates, das hipóteses divergentes, das dúvidas, do confronto de ideias, de informações discordantes. Assim, a sala de aula (presencial ou virtual), deve ser encarada como um laboratório de simulação, onde se busca simular os grandes eventos da literatura, das artes, da filosofia, das ciências etc. Pretende-se, então, atingir objetivos científicos, artísticos, literários e técnicos no mais alto grau possível, indo ao encontro das funções da universidade perante a sociedade (BECKER, 2012). A partir disso, é possível expor conteúdos formalizados, em que o professor reconhecerá o seu educando como um sujeito histórico (com uma história de conhecimentos já percorridos) e não como um mero receptor de conhecimentos dados.

Contudo, com a necessidade de implementar o ERE, foi preciso adequar a sala de aula ao contexto remoto, em que os conteúdos trabalhados, o diálogo e os debates realizados e as atividades tiveram de atender às demandas de uma nova modalidade de ensino. Por sua vez, os alunos tiveram de se adaptar rapidamente a esse novo modelo de educação. Alguns professores, frente a esse novo desafio, acabaram por assumir mais uma função, passaram a fazer as vezes de orientadores educacionais neste processo (CERRI, 2020). Tal situação pode ter acarretado um acúmulo de trabalho para os professores, prejudicando seu ensino. Até mesmo os docentes que buscam realizar uma prática de educação libertadora, ao ficarem sobrecarregados e cansados, com dificuldade de planejar suas aulas, podem ter se tornado reféns de uma prática calcada na transmissão de conteúdos. Paulo Freire (2018) alerta que ao narrar-se conteúdos que são cortes de realidade desconexos da totalidade, transforma-se a palavra em algo vazio, em verbosidade alienada e alienante. Uma educação bancária para tornar-se libertadora deve se despir de sua exterioridade alienada e alienante, transformando-se em uma força de transformação e de libertação (FREIRE, 1967).

Assim, diante das condições impostas pelo contexto remoto e da necessidade de adaptação dos educandos ao ERE, tanto o trabalho dos professores quanto a aprendizagem dos educandos podem ter se tornado precárias. Alerta-se, então, quanto ao risco de se estabelecer como padrão, no ERE, a educação bancária em sua 
implementação e prática na educação superior. E da mesma forma, defende-se o momento como oportuno para se estabelecer a educação problematizadora e se repensar a prática tradicional, de modo que se oportunize a construção de conhecimento coletivo por meio de espaços virtuais que permitam que professores e estudantes tenham liberdade para realizarem debates, apresentar ideias, hipóteses e ponderações divergentes e com isso se tornem protagonistas de sua educação.

\section{CONSIDERAÇÕES FINAIS}

Este ensaio buscou problematizar a adoção e implementação do ERE na educação superior em tempos de pandemia de COVID-19. Para tanto, partiu-se dos entendimentos de Freire (2018) sobre a educação bancária e a educação libertadora. Uma análise de curto prazo, proposta por Cerri (2020), mostrou que nesse cenário os educadores tiveram um acúmulo de estresse, agonia e ansiedade nos seres humanos que trabalharam como máquinas para serem produtivos durante essa situação de pandemia. Desse modo, a proposta apresentada pelos gestores, ao optar-se pelo ERE, não considerou uma série de questões de ordem social, econômica e afetiva. Em termos de ensino, pode ter acabado por priorizar a ideia limitada de educação como mera transmissão de informação, conhecimento e conteúdo.

Acrescentar conteúdos a uma plataforma digital, sem trazer o diálogo e a problematização, coloca os alunos em posição de meros receptores de conhecimento, reduzindo o ensino a uma mera doação. Uma doação do saber "dos que se julgam sábios aos que julgam nada saber" (FREIRE, 2018, p. 81). Urge o entendimento de que Freire nos apresentou há tanto tempo quanto ao ato de ensinar, pois, para ele, "ensinar não é transferir conhecimento, mas criar as possibilidades para a sua própria produção ou construção" (FREIRE, 2019, p. 47).

Desse modo, o ensino, seja na modalidade presencial ou remota, precisa ser pensado e construído a partir dos ideais de libertação, de conscientização, de autonomia, na busca da transformação do mundo. Possivelmente, um ensino que já traz consigo uma prática de educação reprodutora não conseguirá, mesmo que fazendo uso das tecnologias digitais da informação e comunicação (TDICs), apresentar uma prática inovadora.

Outro desafio proposto pelo ERE pode ter sido o quanto o distanciamento geográfico, apesar de todas as tecnologias de comunicação existentes atualmente, pode ter prejudicado a socialização entre os docentes e seus pares, bem como os estudantes e seus colegas que estavam acostumados a encontros presenciais. Um sentimento de solidão pode ter se colocado presente e o diálogo, que implica uma prática libertadora, pode ter sido negligenciado.

Diante disso, entende-se que é relevante dar voz aos professores, entender suas percepções sobre o ERE, perceber sob seu olhar como a educação superior vem enfrentando as complicações que a pandemia de COVID-19 atribuiu a sua prática pedagógica. Contudo, a universidade e seus programas de ensino precisam incluir não 
GUDOLLE, L. S.; BLANDO, A.; FRANCO, S. R. K.

somente os docentes para a construção e avaliação do ERE, mas também seus funcionários e alunos diante dessa situação excepcional.

Nesse sentido, não só o ensino, como um todo, seja na modalidade presencial quanto na remota, precisa ser pensado e repensado a partir de uma prática libertadora. A pergunta que fica, com essa experiência de modalidade remota emergencial e de novos processos que se deram em virtude de contexto, é: como será a sala de aula póspandemia de COVID-19?

Artigo recebido em: 30/03/2021

Aprovado para publicação em: 29/06/2021

\section{EMERGENT REMOTE TEACHING IN HIGHER EDUCATION: A REFLECTION BASED ON PAULO FREIRE}

ABSTRACT: This essay sought to problematize emergency remote education in the context of higher education during the COVID-19 pandemic. To this end, it started with the concept of banking education and the concept of problematizing education proposed by Paulo Freire, in his main work Pedagogy of the oppressed. Questions about emergency remote education are also presented as a traditional practice that continues to perpetuate, despite the use of the Information and Communication Technology (ICT). At the end, the possible difficulties faced by teachers and students in this transition from classroom teaching to emergency remote teaching are addressed.

KEYWORDS: Emergency Remote Education. Pandemic. Banking Education. Problematizing Education.

ENSEÑANZA REMOTA DE EMERGENCIA EN EDUCACIÓN SUPERIOR: UNA REFLEXIÓN BASADA EN PAULO FREIRE

RESUMEN: Este ensayo buscó problematizar la educación remota de emergencia en el contexto de la educación superior durante la pandemia de COVID-19. Para ello, partió del concepto de educación bancaria y el concepto de educación problematizadora propuesto por Paulo Freire, en su obra principal Pedagogía del Oprimido. Las preguntas sobre educación remota de emergencia también se presentan como una práctica tradicional que continúa perpetuándose, a pesar del uso de tecnologías de la información y la comunicación digitales (TDIC). Al final, se abordan las posibles dificultades que enfrentan los docentes y estudiantes en esta transición de la enseñanza presencial a la enseñanza remota de emergencia.

PALABRAS CLAVE: Educación Remota de Emergencia. Pandemia. Educación Bancaria. Educación Problematizadora. 
NOTA

1 - O "ser mais" é a vontade dotada de potência que educandos e educadores devem procurar em atitudes, para fazer emergir uma Educação digna, amorosa e consciente. O conceito de "ser mais" tem o objetivo de que tanto o professor quanto o aluno se formem em união e partam para a ação consciente de se libertarem da opressão (TRINDADE, 2018).

\section{REFERÊNCIAS}

BEHAR, P. A. O Ensino Remoto Emergencial e a Educação a Distância. Disponível em: $<$ https://www.ufrgs.br/coronavirus/base/artigo-o-ensinoremoto-emergencial-e-aeducacao-a-distancia/>. Acesso em: 13 jan. 2021.

BECKER, F. O caminho da aprendizagem em Jean Piaget e Paulo Freire: da ação à operação. Petrópolis, RJ: Vozes, 2010.

BECKER, F. Educação e construção do conhecimento. 2. ed. Porto Alegre: Penso, 2012.

BRASIL. Parecer CNE/CP n5/2020. Reorganização do Calendário Escolar e da possibilidade de cômputo de atividades não presenciais para fins de cumprimento da carga horária mínima anual, em razão da Pandemia da COVID-19. Disponível em: <https://bit.ly/2Zh4JTZ>. Acesso em: 10 dez. 2020.

BRIGHENTE, M. F.; MESQUIDA, P. Paulo Freire: da denúncia da educação bancária ao anúncio de uma pedagogia libertadora. Pro-Posições, Campinas-SP, v. 27, n. 1, p. 155$177,2016$.

BROWNE, L. E. Visões conflitantes do progresso tecnológico. Economic Impact, Rio de Janeiro, v. 49, p. 8-14, jan. 1985.

CERRI, L. N. F. Uma inverdade conveniente: o ensino remoto emergencial. Epistemologia e Práxis Educativa-EPEduc, Teresina-PI, v. 3, n. 3, p. 97-118, 2020,

FIORI, H. M. Prefácio: aprender a dizer a sua palavra. In: FREIRE, Paulo. Pedagogia do Oprimido. $-65^{\circ}$ ed. - Rio de Janeiro/São Paulo: Paz e Terra, 2018. p. 11-30.

FOUCAULT, M. Vigiar e punir: nascimento da prisão. Rio de Janeiro: Vozes, 2009.

FREIRE, P. Educação como prática de liberdade. Rio de Janeiro: Paz e Terra, 1967. 
GUDOLLE, L. S.; BLANDO, A.; FRANCO, S. R. K.

FREIRE, P. Pedagogia da indignação: cartas pedagógicas e outros escritos. São Paulo: Editora UNESP, 2000.

FREIRE, P. Conscientização: teoria e prática da libertação: uma introdução ao pensamento de Paulo Freire. São Paulo: Centauro, 2001.

FREIRE, P. Política e Educação. 1. Ed. - São Paulo: Paz e Terra, 2014.

FREIRE, P. Pedagogia do Oprimido. $-65^{\circ}$ ed. - Rio de Janeiro/São Paulo: Paz e Terra, 2018.

FREIRE, P. Pedagogia da Autonomia: saberes necessários à prática educativa. $59^{\circ}$ ed. Rio de Janeiro/ São Paulo: Paz e Terra, 2019.

MARTINS, R. X. A covid-19 e o fim da educação a distância: um ensaio. EmRede -Revista de Educação a Distância, Porto Alegre, v. 7, n. 1, p. 242-256, 2020.

PIMENTA, S. G.; ANASTASIOU, L. G. Docência no Ensino Superior. São Paulo: Cortez, 2002.

TRINDADE, M. A. O conceito de "ser mais" em Paulo Freire e a relação professor-aluno. Revista COMFILOTEC, São Paulo, v. 7, n. 4, p. 170-181, 2018.

UFRGS. Resolução no 025, de 27 de julho de 2020, documento que estabelece a regulamentação do Ensino Remoto Emergencial (ERE), na Universidade Federal do Rio Grande do Sul. Disponível em: <http://www.ufrgs.br/cepe/res-025-ensino-remotoemergencial-ere-versao-pagina $>$. Acesso em: 28 fev. 2021.

LUCAS SOCOLOSKI GUDOLLE: Doutorando em Informática na Educação na Universidade Federal do Rio Grande do Sul (PGIE-UFRGS) e bolsista CAPES. Mestre em Administração com ênfase em Recursos Humanos (PPGA-UFRGS). Professor EBTT 40h Dedicação Exclusiva no Instituto Federal de Roraima (IFRR) no Campus Avançado Bonfim. Bacharel em Administração.

Orcid: https://orcid.org/0000-0002-6037-1116

E-mail: lucas.gudolle@ifrr.edu.br

AlessandRa Blando: Doutoranda do Programa de Pós-Graduação em Educação da Faculdade de Educação da Universidade Federal do Rio Grande do Sul (UFRGS). Mestra em Educação (UFRGS). Técnica em assuntos educacionais na Universidade Federal do Rio Grande do Sul. Licenciatura em Pedagogia.

Orcid: https://orcid.org/0000-0001-5256-5984

E-mail: blando_ale@hotmail.com

Inter-Ação, Goiânia, v. 46, n. ed.especial, p. 1178-1189, set. 2021. Disponível em: <http://dx.doi.org/10.5216/ia.v46ied.especial.68422>. 
Sérgio Roberto Kieling Franco: Doutor em Educação pela Universidade Federal do Rio Grande do Sul. Professor Titular da Universidade Federal do Rio Grande do Sul (UFRGS). Coordenador do Programa de Pós-Graduação em Educação da Faculdade de Educação da Universidade Federal do Rio Grande do Sul (UFRGS).

Orcid: https://orcid.org/0000-0002-1221-1310

E-mail:srkfranco@smail.com

Este periódico utiliza a licença Creative Commons Attribution 3.0, para periódicos de acesso aberto (Open Archives Initiative - OAI). 